\title{
Utilization of a Self- Care Educational Program for Alleviating Chemotherapy Induced Physical Side Effects
}

\author{
Amina Mohamed Rashad El-Nemer ${ }^{1}$, Maha Ibrahim Ismail El-Zafrani², \\ Hanan El-Sayed Mohamed El-Sayed ${ }^{1}$, Om Hashim Mahmoud Mahmoud Saadoon ${ }^{1}$ \\ ${ }^{1}$ Woman's Health \& Midwifery Nursing department, Faculty of Nursing, Mansoura University, Mansoura ,Egypt \\ ${ }^{2}$ Oncology Medicine department, Oncology Center, Faculty of Medicine, Mansoura University, Mansoura ,Egypt
}

\author{
Email address: \\ drtamer2010@yahoo.com (O. H. M. M. Saadoon)
}

\section{To cite this article:}

Amina Mohamed Rashad El-Nemer, Maha Ibrahim Ismail El-Zafrani, Hanan El-Sayed Mohamed El-Sayed, Om Hashim Mahmoud Mahmoud Saadoon. Utilization of a Self- Care Educational Program for Alleviating Chemotherapy Induced Physical Side Effects. Journal of Cancer Treatment and Research. Vol. 3, No. 1, 2015, pp. 8-16. doi: 10.11648/j.jctr.20150301.12

\begin{abstract}
Breast cancer is the most common cancer among women of both developed and developing countries. It is one of the leading causes of deaths in females. The aim of this study was to evaluate the utilization of a self-care educational program for alleviating chemotherapy induced physical side effects. A quasi - experimental design was used. The study was conducted at outpatient clinics at Oncology Center at Mansoura university Hospital. The study subjects included eighty mastectomised women receiving parenteral adjuvant chemotherapy for the first time. Subjects were divided randomly into two groups: the intervention group obtained a self- care educational program while the control group received the routine care. Three tools were used for data collection (An interview questionnaire sheet, Modified memorial (chemotherapy) symptoms assessment scale\& Modified self- care diary scale). Study results showed that self- care educational program is effective on alleviating physical side effects of chemotherapy. The study recommended the important of teaching such educational program in all Egyptian Oncology Centers for alleviating such chemotherapy induced physical side effects.
\end{abstract}

Keywords: Breast Cancer Chemotherapy, Chemotherapy Induced Physical Side Effects, Self-Care

\section{Introduction}

Breast cancer is the most commonly diagnosed cancer for women worldwide. It affects all aspects of an individual's life [1]. Breast cancer is the most common cancer among women of both developed and developing countries accounting for $22.9 \%$ of all female cancers. It is also the leading cause of cancer death in females accounting for $13.7 \%$ of their cancer related mortality [2]. Breast cancer now occupies position number one in all countries of the Arab world. Its incidence is increasing in the developing world due to increased life expectancy, increased urbanization and adoption of western lifestyles [3].

In Egypt, similar to many other countries in the world breast cancer is the most common cancer and accounts for approximately $38 \%$ of the total reported malignancies among Egyptian women where about $20 \%$ of breast cancers occur in women aged $<40$ years [4 \& 5]. Multiple modalities are commonly used in cancer treatment which includes surgery, chemotherapy, radiation therapy, immunotherapy (also called biotherapy), bone marrow transplants, gene, hormone and proton therapy and complementary medicine such as herbals, vitamins, chemicals, diet, meditation, massage, acupuncture and body mind therapy [6]. Chemotherapy is based on giving medications that have toxic effect towards rapidly multiplying cancer cells as they interfere with their uncontrolled growth and multiplication [7].

However, some rapidly dividing normal cells will be affected by chemotherapy, such as those lining the gastrointestinal tract, bone marrow cells and hair follicles. These side effects are commonly found in all patients. The patient would suffer from uncomfortable feelings .These symptoms might include fatigue, anorexia, nausea, vomiting, mouth sores and low white blood cell counts and low platelets which can cause abnormal bleeding [8 \& 9].

As regarding the fatigue as a side effect of chemotherapy, it is defined as distressing, persistent, subjective sense of physical, emotional and or cognitive tiredness or exhaustion related to cancer or cancer treatment that isn't proportional to recent activity and interferes to usual functioning. 
Chemotherapy induced fatigue is a significant and highly prevalent clinical problem and it is long lasting and characterized by a significant temporal variability [10].

Symptoms of fatigue often is not continually present but comes and goes in a somewhat roller coaster fashion, it affects all aspects of patients' lives and decreases quality of life, it is fluctuate over time and peaks in the days immediately after chemotherapy administration [11]. Patients with cancer who were treated by conventional three- or fourweek regimens reported high levels of fatigue for the first four to five days after chemotherapy then fatigue decreased steadily in subsequent days until around day 15[11].

Concerning the nausea and vomiting, the degree of nausea and vomiting varies from mild -moderate to severe according to many factors as type and dose of chemotherapy, radiation to the stomach area, the cancer itself, medications, infection, severe constipation and anxiety or worrying [12]. Combination of nausea and vomiting following chemotherapy and anxiety can lead to the development of anticipatory nausea which can debilitate the patient for days before their chemotherapy appointment [13]. The oral cavity is frequently a prime target for mucotoxicity because of the effect that cancer therapies have on normal cells. Mucositis can be a serious problem, it refers to the inflammatory process involving the mucous membranes of the oral cavity and the gastrointestinal tract, this mucotoxicity is often present throughout the gastrointestinal tract as well another mucous membranes in the body [14].

The ease of assessing the oral cavity allows it to serve as a "window" of potential mucotoxicity in other areas of the body. In addition to the healthy cells in the lining of the mouth are affected; it can lead to a number of side effects as soreness and ulceration of the mouth, mouth infections, oral thrush, loss of appetite\& dry mouth [15].

Related to hair loss, as one of dermatologic conditions resulting from chemotherapy carry anxiety and emotional distress [16]. Hair loss is considered one of the most traumatic factors in cancer patient care and occurs with an estimated incidence of $65 \%$ also hair loss negatively affects a patient's perception of appearance, body image, sexuality, and self-esteem [16 \& 17].

Moreover, patients feel deprived of their privacy because the hair loss is readily interpreted by the lay public as associated with having cancer, some chemotherapy treatments may cause, some or complete hair loss. Patient may lose her hair from all parts of the body that happens about 2 to 3 Weeks after the 1 st cycle of treatment [18 \& 19]. Cytotoxic chemotherapeutic agents has many systemic affect specially involving rapidly proliferating organs, such as skin, hair, and the gastrointestinal tract manifesting as exfoliative dermatitis and alopecia [20]. The nails have transverse line parallel to the lunula across the entire nail bed with no palpable ridges which were white and non-blanching, these lines are known as Mees' lines (true leukonychia) [20\& 21]. During chemotherapy cycles the skin may be darken, peel or become dry and itchy and more sensitive to the sun [22].

As Chemotherapy is frequently carried out on an outpatient basis and in some cases at the inpatient units attached to the chemotherapy department over an extended period of time. Thus, the patients must assume major responsibility of their own care, encouraged and motivated to continue the regimen even when the treatment produces side effects [9].

Self- care is defined as the practice of activities that individuals personally initiate and perform on their own behalf to maintain life, health and wellbeing [23]. Processes for achieving these goals include selecting healthy lifestyles, self- monitoring and assessing symptoms, perceiving and assigning meaning to symptoms, evaluating the severity of the situation, and determining treatment alternatives [24]. Provision of information to patients is one of the most important factors of supportive cancer care across the whole cancer continuum. The goal of providing information is to prepare patients for their treatment, to increase adherence to therapy, to increase their abilities to cope with the illness and to promote recovery [25]. Teaching patients about their treatment reduces fear, increases self-confidence, improves compliance and enhances their participation in self-care.

Patients can control chemotherapy induced fatigue by doing simple measures given by the nurse as going to bed earlier than usual, also getting up later than usual, taking more naps, getting outdoor as walking or exercise, keeping busy to get mind off it e.g. listening to music or watching TV, drink more beverages with caffeine like tea or coffee, planning activities of day to cope with fatigue, saving energy for the most important things, joining a support group, limiting amount of caffeine and alcohol, keeping a diary of how feeling each day and reporting any changes in energy level to the doctor or nurse [26, $27 \& 28]$.

As regarding the nausea and vomiting, the nurse should instruct women to apply self-care strategies to alleviate nausea \& vomiting from chemotherapy by avoiding the sight or smell of hot food, eating small frequent meals, avoiding spicy food, getting fresh air, drinking clear fluids including water, soup and juice, modifying diet in attractive way, drinking ginger raw sugar fluid, eating more fresh fruits and vegetables and smell flavor of orange or lemon [29 \& 26].

The nurse has an important role in advising women about simple measures to alleviate mucositis as helping women to obtain simple information this side effect so that good oral hygiene habits, use the softest bristle brush to clean the teeth and to prevent unnecessary abrasions to the gums and oral mucosa, clean the mouth with a mild non astringent antiseptic mouthwash, e.g. mixture of 1 quart plain water, $1 / 2$ teaspoon table salt and $1 / 2$ teaspoon baking used after meals and at bed time and prevent cracked lips by using Vaseline[30 \& 31]. Care of hair must be done by using mild shampoo such as baby shampoo, educate patient about using a soft hair brush or wide tooth comb as the scalp can become sensitive. Teaching the patient to wear sunscreen on the scalp and use a toweling turban at night so that hair lost in bed can be easily and less distressingly dealt with it [18].

In order to alleviate skin and nail problems, patients must do simple tips as showering using a moisturizing soap or a 
soap replacement. After showering, gently drying the skin with a soft towel and avoiding rub it too hard, using moisturizing lotion or cream on large areas to stop the dryness, dust corn flour over the itchy parts of the skin, wearing loose non-restricting clothing, choose cotton fabric instead of rough wool or synthetic fibers, avoid removing hair until the skin is completely healed, drink plenty of water, protect the skin from direct sun exposure, maintain gentle care of the nails, wear light-colored pants, long-sleeve cotton shirts, and hats with wide brims, don't use tanning beds, place a cool, wet cloth where your skin hurts and wearing protective gloves during gardening or cleaning the house [22]

Oncology nurses therefore, are responsible for encouraging and promoting proper self-care of the patients being treated with chemotherapy. Self-care behaviors are preparation before receiving chemotherapy, self-conduct during and after chemotherapy and self-care at home. By doing so, patients can return to normal life in their own environment and society [24].

\section{Significance \& Aim of the Study}

Educating patients and families about self-care strategies to alleviate side effects and problems of chemotherapy is important for a number of reasons; firstly, it is proposed that most people will spontaneously respond to symptoms with some self-care actions and secondly, effective selfmanagement behaviors can help cancer patients to take an active and positive approach to their cancer experience; moreover there is a growing body of evidence that when used as an adjunct to other biomedical interventions, many nonpharmacological interventions can effectively relieve symptoms.

So the aim of this study was to evaluate the utilization of a self- care educational program for alleviating chemotherapy induced physical side effects.

\section{Materials \& Methods}

\subsection{Study Design}

A quasi experimental design was used in this study.

\subsubsection{Study Setting}

The study was conducted at oncology center, Mansoura University Hospital in the period from January 2013 to September 2013.

\subsubsection{Sample Size}

The study subjects included 80 mastectomized women divided into control and intervention groups.

\subsubsection{Inclusion Criteria}

Women accepting to participate in the study, receiving adjuvant chemotherapy for the first time, aged from 20-60 years and above and able to read \& write.

\subsubsection{Tools of Data Collection}

Three tools were used for data collection, namely sociodemographic sheet, modified Memorial Symptoms assessment scale\& modified self- care diary scale.

Tool I Included sociodemographic characteristics of women as name, age, education, occupation, residence, marital status, telephone number and income level.

Tool II Modified Memorial Symptoms assessment scale using 4 and 5 likert scale, which contained the most common side effects of chemotherapy as fatigue, nausea, vomiting, oral sores, hair loss \& skin problems. It contained three dimensions as potentially relevant to symptoms evaluation; (1) frequency with which the symptoms were occurred; (2) severity of the symptoms \& the distress it produced [32, $33 \&$ 34].

Tool III Included Modified self- care diary scale, this diary contained a checklist of side effects commonly experienced by women receiving parenteral chemotherapy for breast cancer and a list of self-care activities aimed at managing these side effects. The purpose of the diary was to quantify women's involvement in self-care during the course of their chemotherapy treatment; the diary entailed mainly closed ended questions it was contained two items as performance of self-care strategies and effect of self- care strategies on alleviating chemotherapy problems by Yes or No answers [35].

\subsection{Field Work}

The data collection started from January 2013 until September 2013. It included the control and intervention groups. Women were present at outpatient clinic, Oncology Center at Mansoura University Hospital to receive chemotherapy that was divided into 6 cycles; there were 21 days as a period of rest between each cycle and the other. After securing official permission to carry out the study, during the $1^{\text {st }}$ cycle of chemotherapy the researcher met each woman that had the included criteria in the outpatient clinic on days of Sunday, Monday, Wednesday and Thursday, which were the days of medical oncology and introduced herself, explained that her role to help them and obtained informed consent from each woman to implement the study.

Firstly the researcher collected data of the control group from the period of $6 / 1 / 2013$ until $9 / 5 / 2013$, the researcher met women in the control group 2 times. At the first time during the first cycle of chemotherapy, the researcher asked women questions regarding socio-demographic data as name, age, education, occupation, residence, marital status, telephone number and income level.

The second time during the $6^{\text {th }}$ cycle of chemotherapy, the researcher met women in the control group to assess their side effects and problems of chemotherapy using modified memorial symptoms assessment scale (MMSAS) and assessed their self-care strategies to alleviate problems of chemotherapy using modified self-care diary scale (MSCDS).

From the period of $12 / 5 / 2013$ until 12/9/2013 the researcher met women included in the intervention group, introduced herself and explained her role. At the first cycle of chemotherapy socio-demographic data of women were collected. Directly the researcher began to give the $1^{\text {st }}$ session of the program included side effects of chemotherapy as 
fatigue, nausea, vomiting, mouth sores, hair loss \& changes in skin that occurred during chemotherapy treatment was given to group of 3-4 women at the first cycle of treatment, and the $2^{\text {nd }}$ session included information about self- care strategies to alleviate such side effects of chemotherapy, each session lasted 30 minutes separated by 10 minutes as a period of rest. After that the researcher gave booklet to each woman in the intervention group.

At the second cycle of treatment, the $3^{\text {rd }}$ session was given contained revision of the content of the $1^{\text {st }} \& 2^{\text {nd }}$ sessions that was given at the $1^{\text {st }}$ cycle of chemotherapy lasted 45 minutes.

At the $6^{\text {th }}$ cycle of chemotherapy each woman involved in the intervention group was assessed for chemotherapy problems (side effects) and self-care strategies using (Memorial Symptoms Assessment Scale \& Self- Care Diary Scale).

\subsection{Statistical Analysis}

Data entry and statistical analysis were done using SPSS version 15.0 software package.

Data were presented using descriptive statistics in the form of frequencies and percentages for qualitative variable. Mean $\&$ standard deviation for quantitative variables. Qualitative categorical variables were compared using chi-square test \& Mann Whitney test Statistical significance was considered at p-value $<0.05$.

\section{Results}

Table (1) demonstrates the socio-demographic characteristics of the studied groups. The table reveals that the ages of women in both groups ranged from $20 \geq 60$ years; with the mean age of $50.63 \pm 10.93$ in the control group and $48.45 \pm 12.84$ in the intervention group. However the relation between them wasn't significant (X $2=2.88 \& \mathrm{p}=0.24$ ). Also there were no statistical significant differences regarding residence, marital status, educational level, occupation \& income level among control and intervention groups $(\mathrm{p}>0.05)$.

Table (2) showed frequency of side effects of chemotherapy as reported by women in both groups. It was found that side effects of chemotherapy as (fatigue- nausea \& vomiting) were decreased in frequency in intervention group compared to control group. As regards to symptoms of mouth sores, hair loss \& changes in skin not evaluated. There were highly statistical significant differences among intervention and control groups $(\mathrm{p}=0.000)$.

Table (3) Indicated that side effects of chemotherapy as (fatigue- nausea- vomiting- hair loss \& changes in skin except mouth sores) were decreased in it's severity in intervention group compared to control group. There were highly statistical significant differences among intervention and control groups $(\mathrm{p}=0.000)$.

Table (4) represented the effect of side effects of chemotherapy as reported by women in both groups using memorial symptoms assessment scale. There were highly statistical significant improved in effect of side effects of chemotherapy among intervention and control groups $(\mathrm{p}=$ 0.000) concerning (fatigue- nausea- vomiting- hair loss \& changes in skin except mouth sores).

Table (5) clarified effect of self- care strategies carried out by women of the study groups to alleviate fatigue, nausea, vomiting \& mouth sores. There were highly statistically significant differences between intervention and control group in all self -care strategies $(\mathrm{p}=0.000)$.

Table (6) demonstrated that $(90 \%, 85 \%, 80 \%, 22.5 \%$, $22.5 \%$ respectively) of women in intervention group reported positive effect of self- care strategies that were applied to alleviate hair loss compared to control group. So there were highly statistical significant differences between two groups of the study $(\mathrm{p}=0.000)$.

Table (1). Number, percentage distribution and mean score of the study groups according to socio-demographic characteristics.

\begin{tabular}{|c|c|c|c|c|c|c|}
\hline \multirow{2}{*}{$\begin{array}{l}\text { Socio-demographic } \\
\text { characteristics }\end{array}$} & \multicolumn{2}{|l|}{ Control $n=40$} & \multicolumn{2}{|c|}{ Intervention $\mathrm{n}=\mathbf{4 0}$} & \multirow{2}{*}{$\mathbf{X}^{2}$} & \multirow{2}{*}{ P-value } \\
\hline & No & $\%$ & No & $\%$ & & \\
\hline Age (in years) Mean \& SD & $50.63 \pm 10.93$ & & $48.45 \pm 12.84$ & & & \\
\hline \multicolumn{7}{|l|}{ Residence } \\
\hline Rural & 32 & 80 & 25 & 62.5 & \multirow[t]{2}{*}{2.99} & \multirow[t]{2}{*}{0.08} \\
\hline Urban & 8 & 20 & 15 & 37.5 & & \\
\hline \multicolumn{7}{|l|}{ Marital status } \\
\hline Single & 2 & 5 & 2 & 5 & \multirow{4}{*}{1.13} & \multirow{4}{*}{0.77} \\
\hline Married & 28 & 70 & 30 & 75 & & \\
\hline Divorced & 1 & 2.5 & 0 & 0.0 & & \\
\hline Widow & 9 & 22.5 & 8 & 20 & & \\
\hline \multicolumn{7}{|l|}{ Educational level : } \\
\hline Read and write & 26 & 65 & 23 & 57.5 & \multirow{3}{*}{0.49} & \multirow{3}{*}{0.78} \\
\hline Diplomat degree & 11 & 27.5 & 13 & 32.5 & & \\
\hline baccalaureate & 3 & 7.5 & 4 & 10 & & \\
\hline \multicolumn{7}{|l|}{ Occupation: } \\
\hline Worked & 4 & 10 & 9 & 22.5 & \multirow[t]{3}{*}{2.30} & \multirow[t]{2}{*}{0.13} \\
\hline Not worked & 36 & 90 & 31 & 77.5 & & \\
\hline \multicolumn{6}{|l|}{ Income } & \\
\hline$<500$ L.E. & 22 & 55 & 23 & 57.5 & \multirow{3}{*}{0.29} & \multirow{3}{*}{0.87} \\
\hline $500<1000$ L.E. & 14 & 35 & 12 & 30 & & \\
\hline$\geq 1000$ L.E. & 4 & 10 & 5 & 12.5 & & \\
\hline
\end{tabular}


Table (2). Mean ranks regarding the frequency of physical side effects of parenteral chemotherapy for the study groups using modified memorial symptoms assessment scale.

\begin{tabular}{|c|c|c|c|c|c|c|c|}
\hline \multirow{2}{*}{ Items } & \multicolumn{2}{|l|}{ Control $(n=40)$} & \multicolumn{2}{|c|}{ Intervention $(n=40)$} & \multirow{2}{*}{$\begin{array}{l}\text { Mann } \\
\text { Whitney }\end{array}$} & \multirow{2}{*}{$\mathbf{z}$} & \multirow{2}{*}{ p-value } \\
\hline & Mean rank & Sum of ranks & Mean rank & Sum of ranks & & & \\
\hline 1- Fatigue & 56.01 & 2240.5 & 24.99 & 999.5 & 179.5 & 6.20 & $0.000^{*}$ \\
\hline 2- Nausea & 55.44 & 2217.5 & 25.56 & 1022.5 & 202.5 & 5.94 & $0.000^{*}$ \\
\hline 3- Vomiting & 54.72 & 2189 & 26.28 & 1051 & 231 & 5.68 & $0.000^{*}$ \\
\hline
\end{tabular}

* Significant at $\mathrm{p}<0.05$

Table (3). Mean ranks regarding the severity of physical side effects of parenteral chemotherapy for the study groups.

\begin{tabular}{llllllll}
\hline \multirow{2}{*}{ Items } & Control $(\mathbf{n}=\mathbf{4 0})$ & \multicolumn{3}{l}{ Intervention $(\mathbf{n}=\mathbf{4 0})$} & \multirow{2}{*}{ Mann Whitney } & $\mathbf{z}$ & p-value \\
\cline { 2 - 6 } & Mean rank & Sum of ranks & Mean rank & Sum of ranks & & 3.62 & $0.000^{*}$ \\
1- Fatigue & 49.16 & 1966.5 & 31.84 & 1273.5 & 453.5 & 4.39 & $0.000^{*}$ \\
2- Nausea & 51.40 & 2056 & 29.60 & 1184 & 364 & 3.91 & $0.000^{*}$ \\
3- Vomiting & 50.21 & 2008.5 & 30.79 & 1231.5 & 411.5 & 1.26 & 0.21 \\
4-Mouth sores & 43.54 & 1741.5 & 37.46 & 1498.5 & 678.5 & 4.51 & $0.000^{*}$ \\
5-Hair loss & 51.90 & 2076 & 29.10 & 1164 & 344 & 6.33 & $0.000^{*}$ \\
6-Changes in skin & 56.40 & 2256 & 24.60 & 984 & 164 & & \\
\end{tabular}

* Significant at $\mathrm{p}<0.05$

Table (4). Mean ranks regarding the effect of physical side effects of parenteral chemotherapy for the groups.

\begin{tabular}{|c|c|c|c|c|c|c|c|}
\hline \multirow{2}{*}{ Items } & \multicolumn{2}{|c|}{ Control $(n=40)$} & \multicolumn{2}{|c|}{ Intervention $(n=40)$} & \multirow{2}{*}{$\begin{array}{l}\text { Mann } \\
\text { Whitney }\end{array}$} & \multirow{2}{*}{$\mathbf{z}$} & \multirow{2}{*}{ p-value } \\
\hline & Mean rank & Sum of ranks & Mean rank & Sum of ranks & & & \\
\hline 1- Fatigue & 50.41 & 2016.5 & 30.59 & 1223.5 & 403.5 & 3.96 & $0.000^{*}$ \\
\hline 2- Nausea & 56.01 & 2240.5 & 24.99 & 999.5 & 179.5 & 6.10 & $0.000^{*}$ \\
\hline 3- Vomiting & 55.68 & 2227 & 25.32 & 1013 & 193 & 5.97 & $0.000 *$ \\
\hline 4-Mouth sores & 44.35 & 1774 & 36.65 & 1466 & 646 & 1.56 & 0.12 \\
\hline 5-Hair loss & 57.11 & 2284.5 & 23.89 & 955.5 & 135.5 & 6.60 & $0.000^{*}$ \\
\hline 6-Changes in skin & 56.70 & 2268.5 & 24.30 & 972 & 152 & 6.37 & $0.000 *$ \\
\hline
\end{tabular}

* Significant at $\mathrm{p}<0.0 .05$

Table (5). Number\& percentage distribution of the study groups regarding to effect of self-care strategies to alleviate fatigue, nausea, vomiting\& mouth sores.

\begin{tabular}{|c|c|c|c|c|c|c|c|c|c|c|}
\hline \multirow{3}{*}{ Items } & \multicolumn{4}{|c|}{ Control $(n=40)$} & \multicolumn{4}{|c|}{ Intervention $(\mathrm{n}=\mathbf{4 0})$} & \multirow{3}{*}{$\mathbf{X} 2$} & \multirow{3}{*}{ p-value } \\
\hline & \multicolumn{2}{|c|}{ yes } & \multicolumn{2}{|l|}{ no } & \multicolumn{2}{|c|}{ yes } & \multicolumn{2}{|l|}{ no } & & \\
\hline & $\mathbf{n}$ & $\%$ & $\mathbf{n}$ & $\%$ & $\mathbf{n}$ & $\%$ & $\mathbf{n}$ & $\%$ & & \\
\hline A-Fatigue & & & & & & & & & & \\
\hline 1-Adequate rest & 16 & 40 & 24 & 60 & 34 & 85 & 6 & 15 & 17.28 & $0.000^{*}$ \\
\hline 2-Sleep at least 8hrs & 5 & 12.5 & 35 & 87.5 & 27 & 67.5 & 13 & 32.5 & 25.21 & $0.000^{*}$ \\
\hline 3-Increase fluid intake & 10 & 25 & 30 & 75 & 29 & 72.5 & 11 & 27.5 & 18.06 & $0.000^{*}$ \\
\hline 4-exercise or walking & 6 & 15 & 34 & 85 & 31 & 77.5 & 9 & 22.5 & 31.43 & $0.000^{*}$ \\
\hline 5-Reading or listening to Quran & 9 & 22.5 & 31 & 77.5 & 27 & 67.5 & 13 & 32.5 & 16.36 & $0.000^{*}$ \\
\hline$\frac{\text { B)Nausea\& Vomiting }}{1-\text { Small frequent meals }}$ & 10 & 25 & 30 & 75 & 30 & 75 & 10 & 25 & 20 & $0.000^{*}$ \\
\hline 2-Easy digested food & 6 & 15 & 34 & 85 & 30 & 75 & 10 & 25 & 29.09 & $0.000^{*}$ \\
\hline 3-Avoiding spicy food & 7 & 17.5 & 33 & 82.5 & 33 & 82.5 & 7 & 17.5 & 33.80 & $0.000^{*}$ \\
\hline 4-Eat cold not hot food & 1 & 2.5 & 39 & 97.5 & 31 & 77.5 & 9 & 22.5 & 46.88 & $0.000^{*}$ \\
\hline 5-Oral hygiene & 13 & 32.5 & 27 & 67.5 & 29 & 72.5 & 11 & 27.5 & 12.83 & $0.000^{*}$ \\
\hline$\frac{\text { C-Mouth sores }}{1-\text { Oral self-examination }}$ & 0 & 0.0 & 40 & 100 & 30 & 75 & 10 & 25 & 48 & $0.000^{*}$ \\
\hline 2-Lip moisturizer & 8 & 20 & 32 & 80 & 35 & 87.5 & 5 & 12.5 & 36.66 & $0.000 *$ \\
\hline 3-Sucking candy & 2 & 5 & 38 & 95 & 27 & 67.5 & 13 & 32.5 & 33.81 & $0.000 *$ \\
\hline 4-Avoid oral wash contain alcohol & 4 & 10 & 36 & 90 & 30 & 75 & 10 & 25 & 34.58 & $0.000 *$ \\
\hline 5-Increase fluid intake & 7 & 17.5 & 33 & 82.5 & 33 & 82.5 & 7 & 17.5 & 33.80 & $0.000 *$ \\
\hline
\end{tabular}

* Significant at $\mathrm{p}<0.05$ 
Table (6). Number \& percentage distribution of the study groups regarding the effect of self-care strategies to alleviate hair loss \& skin problems.

\begin{tabular}{|c|c|c|c|c|c|c|c|c|c|c|}
\hline \multirow{3}{*}{ Items } & \multicolumn{4}{|c|}{ Control $(n=40)$} & \multicolumn{4}{|c|}{ Intervention $(n=40)$} & \multirow{3}{*}{$\mathbf{X}^{2}$} & \multirow{3}{*}{ p-value } \\
\hline & \multicolumn{2}{|c|}{ yes } & \multicolumn{2}{|l|}{ no } & \multicolumn{2}{|c|}{ yes } & \multicolumn{2}{|l|}{ no } & & \\
\hline & $\mathbf{n}$ & $\%$ & $n$ & $\%$ & $\mathrm{n}$ & $\%$ & $n$ & $\%$ & & \\
\hline \multicolumn{11}{|l|}{ A-Hair loss } \\
\hline 1-Cut hair & 5 & 12.5 & 35 & 87.5 & 32 & 80 & 8 & 20 & 36.66 & $0.000 *$ \\
\hline 2-Wearing a wig & 2 & 5 & 38 & 95 & 9 & 22.5 & 31 & 77.5 & 5.17 & 0.02 \\
\hline 3-Gently wash hair with shampoo & 5 & 12.5 & 35 & 87.5 & 36 & 90 & 4 & 10 & 48.08 & $0.000^{*}$ \\
\hline 4-Gently drying hair & 17 & 42.5 & 23 & 57.5 & 34 & 85 & 6 & 15 & 16.63 & $0.000^{*}$ \\
\hline 5-Use sun visor & 4 & 10 & 36 & 90 & 9 & 22.5 & 31 & 77.5 & 32 & 0.13 \\
\hline $\begin{array}{l}\text { B- Skin problems } \\
\text { 1-Showering quickly }\end{array}$ & 9 & 22.5 & 31 & 77.5 & 34 & 85 & 6 & 15 & 31.43 & $0.000^{*}$ \\
\hline 2-Use a moisturizing cream & 10 & 25 & 30 & 75 & 35 & 87.5 & 5 & 12.5 & 31.75 & $0.000^{*}$ \\
\hline 3-Avoid exposure to sun & 11 & 27.5 & 29 & 72.5 & 36 & 90 & 4 & 10 & 32.24 & $0.000^{*}$ \\
\hline 4-Wear light clothes & 6 & 15 & 34 & 85 & 32 & 80 & 8 & 20 & 33.89 & $0.000^{*}$ \\
\hline
\end{tabular}

* Significant at $\mathrm{p}<0.05$

\section{Discussion}

Self-care is behavior initiated or performed by individuals on their own to behalf, to safe life and promote health. Selfcare suggests that individuals use their resources, including personal attributes such as knowledge, skills, positive attitudes, determination, courage, and optimism, to improve poor health [36 \& 37]. Concerning the side effects of chemotherapy as reported by women, it was found in the present study that frequency, severity \& effect of side effects of chemotherapy as fatigue, nausea, vomiting, mouth sores, hair loss, were decreased in intervention group compared to control group.

The researcher interpreted that as increasing women's knowledge in intervention group about self- care educational program had a positive effect on women and alleviating side effects of chemotherapy than those in control group, although women in control group reported that some symptoms had decreased in frequency, severity \& it's effect may be due to some of women in control group reading about chemotherapy or searching for information on the world wide or applying simple self- care strategies that they found them effective on alleviating side effects of chemotherapy.

These were in agreement with Laugsand et al., mentioned that chemotherapy-related symptoms are described as preventable symptoms [38]. Also Kinnane, reported that audiovisual resources within chemotherapy education have recently promote higher recall of symptom information [39]. In addition to many studies have stressed that quality of life may be improved and adherence to the disease and treatment processes may be increased by education [28, 40, $41 \& 42]$. Concerning nausea \& vomiting, in the studies by Aslan and Vural, Aranda et al., \& Kav and Akdemir, investigating the effect of education on symptom management in patients taking chemotherapy a decrease was observed in posttreatment frequency, severity \& effect of nausea and vomiting [43, $44 \& 45]$.

Concerning self-care strategies to alleviate chemotherapyrelated fatigue. The findings of the current study showed that the most performed self-care strategies by women to alleviate fatigue were obtaining adequate rest, increasing intake of juice and fluids \& doing distractive activity as reading or listening to music and women reported that significantly effective strategies on alleviating fatigue.

These were in agreement with previous study that reported that patients may perform self-care activities to conserve energy and to alleviate fatigue such as napping, sleeping more than usual, distracting themselves, or modifying their activities, modification of activity and rest pattern\& changing of sleep-wake patterns reported and these activities provided partial relief [46].

Also a growing body of evidence suggested that physical exercise (walking, swimming, yoga, resistance training) and interventions reduce stress and increase psychosocial support (counseling, stress management, coping strategies) can help reduce fatigue [ $47 \& 48$ ].

Concerning self-care strategies to alleviate chemotherapy induced nausea $\&$ vomiting. The findings of the current study showed that the most performed self-care strategies by women to alleviate nausea \& vomiting were eating easy digested food, avoiding spicy food, small frequent meals, oral hygiene \& eat cold not hot food.

These were in agreement with Cancer Council, reported that the most performed and helped self-care strategies to alleviate nausea and vomiting were eating easy digested food, avoiding spicy food and eats small frequent meals [49].

Also Thompson et. al pointed that, the majority of patients indicated that receiving nutrition education while going through treatment was very important that helping them to cope nutritional side effects of chemotherapy \& eating a balanced diet [50].

Concerning self-care strategies to alleviate chemotherapyrelated mouth sores, the findings of the current study showed that the majority of women reported that the most performed and helped self-care strategies to alleviate mouth sores were increase fluid intake, avoid oral wash contain alcohol/ use water based mouth moisturizers \& use lip moisturizers. This was ascertained with American Cancer Society mentioned that adequate intake of fluids and avoiding mouth wash contain alcohol were effective measures in reducing 
mucositis or mouth problems caused by chemotherapy [51]. In addition to Miller et. al., stated that increasing participatory role in patients' self-care of mucosities is becoming important as the trend for shorter hospital stay and increasing out-patient chemotherapy are common. Coping with oral health problems at home, without on-hand support of oncology health personnel resulting in patients effectively coping with postchemotherapy self-care improvement through awareness of oral symptoms and other related oral care [52].

Regarding the self-care strategies to alleviate chemotherapy-related hair loss or alopecia, the findings of the current study showed that the majority of women reported that the most performed and helped self-care strategies of hair loss were gently drying hair, gently wash hair with mild shampoo as baby shampoo \& cut hair.

These findings were supported by Frith, \& Macmillan Cancer Resource Centre, were suggested that cutting and shaving hair may serve a multitude of additional functions to prepare self and others for the loss of hair, to gain control over the timing of hair loss, to feel proactive [53 \& 54].

In addition to Kim et.al., Rosman \& McGarvey et al., reported that wigs, hats \& scarves were the most effective way to hide baldness and helped them to reduce alopecia distress [55, 56 \& 57]. Also Frith et al., reported that patients who were well informed about alopecia adjusted and coped with it better than those who were not [53].

As related to self-care strategies to alleviate chemotherapy-related skin $\&$ nail problems. The findings of the current study showed that the most performed and helped self- care strategies to alleviate skin \& nail problems were showering quickly, use a moisturizing cream, avoid exposure to sun\& wear light clothes.

These were in agreement with National Cancer Institute, \& American Cancer Society, Al-Omran et.al., \& Polovich et.al., who were reported that Patients receiving chemotherapy can cope with skin and nail problems by avoid long, hot baths, use a moisturizing soap, apply dryness through take quick showers or sponge baths, don't take cream and lotion while the skin is still moist\& clothes must be light and in layers [58, 59, $60 \& 61]$.

\section{Conclusion}

In the light of the study findings, some important facts can be concluded into: self-care education give further insight into one's being, one's own life's purpose and one's position in life. These three, help one locate oneself( even in the middle of environmental chaos and personal mental conflicts); promote acceptance of ones' situation; open's doors to personal quality and add supports to one's self- in the present study were fatigue, nausea, vomiting, mouth sores, hair loss\& changes in skin. The applied self-care educational program improved to great extent the knowledge and practice of mastectomy women regarding side effects of chemotherapy and how to alleviate them.

meaning leading to development of self- care management traits that promotes self- healing.
The most common alleviated side effects of chemotherapy

\section{Recommendations}

1. Appling self- care educational program in all Egyptian Oncology Centers.

2. The nurse being a key person in the care of cancer patient during the different phases of treatments, she needs a special preparation to this important specialty, as educational strategies should include not only the advanced technology nursing but also the communication and counseling skills needed for caring for cancer patients and their families.

3. Increase the number of qualified nurses at the chemotherapy outpatient clinics to provide the patient and family members with information regarding chemotherapy, its purpose, side effects and how to manage these side effects

4. Pre-service and in-service training program for the purpose of refreshing and updating the knowledge of nurses working with patients receiving chemotherapy about selfcare strategies to alleviate side effects of chemotherapy.

5. Encourage the patient and family members to attend health education and counseling program about chemotherapy related side effects and how to deal and cope with these side effects. Conducting workshops, seminars, or clinical conferences regarding the presence issue could help immensely.

6. Electronic disseminated information regarding chemotherapy side effects\& alleviated practices.

7. Establishing rehabilitation center for cancer patient that focus on physical \& psychological aspect of care.

8. Further researches in the field of oncology nursing should be encouraged by the nursing faculties to reach a better quality of care.

9. Enhancing mass media as TV. about side effects of chemotherapy and self- care strategies to alleviate such side effects.

\section{References}

[1] Wu, T., Liu, Y., \& Chung S. Improving Breast Cancer Outcomes among Women in China: Practices, Knowledge, and Attitudes Related to Breast Cancer Screening, International Journal of Breast Cancer. 2012.

[2] ZeeneldinA. A., Mohamed RamadanM., GaberA., A.,et.al., Clinico-pathological features of breast carcinoma in elderly Egyptian patients: Institute. 25, P. 5-11. 2012.

[3] World Health Organization. Breast Cancer: Prevention and Control. Available at :http://www.WHO.int/ cancer/ detection/ breast cancer/en/ . Accessed in March 9, 2010.

[4] Ibrahim A., Salem M., A., and Hassan R. Outcome of young age at diagnosis of breast cancer in South Egypt. G.J.O. Issue 15,76-83. 2014.

[5] Rennert G., Freedman L., Edwards B., Riels Y., J. Breast cancer incidence in four conties (cyprus, Egypt, Israel and Jordan) of the middle East cancer (on sortium(MECC) compared with USSEER. National Cancer Institute (NIH), Bethesda; 06: 5873. 2006. 
[6] Bruce A. ChabnerB. A., ThompsonE. C. Modalities of Cancer Therapy. Available at //www.merckmanuals.com /professional/hematology_and_oncology. Merck \& Co., Inc.,U.S.A. 2013.

[7] Zawilla N. Breast cancer in Egypt: A fact sheet. Disease Watch the Health, (2)1:8-10.P. 8-11. 2011.

[8] SilverJ., K. Rehabilitation in Women with Breast Cancer. Phys Med Rehabil Clin N.ElsevierInc. 521-537. 2007.

[9] National Cancer Institute. Chemotherapy. Availableat:http://www.ncigo.th/knowledge/chem. 2010.

[10] Diane M., Von A., H., Duck-Hee Kang, et al. Predictors of Cancer- Related Fatigue in Women with Breast Cancer Before, During, and After Adjuvant Therapy. Cancer Nurs, 31(2): 13444. 2008.

[11] Horng-ShiuannWu.,Marylin J., Dodd et al., et.al. Patterns of Fatigue and Effect of Exercise in Patients Receiving Chemotherapy for Breast Cancer Oncology Nursing Forum vol 35 , no 5. 2008 .

[12] Incekol D. \& Murray C. Managing the side effects of chemotherapy. University Health Network. $1^{\mathrm{s}} \mathrm{t}$ ed. P 9-18. 2011.

[13] Corner, J. and Bailey, C. Cancer Nursing: Care in Context. Oxford: Blackwell Scientific. 2008.

[14] Eillers J \& Million R. Clinical Update Prevention and management of Oral Mucositis in Patients with Cancer. Seminars in Oncology Nursing, Elsevier Inc. Vol 27, No 4, 2011. Available at jeilers@nebraskamed.com

[15] Rehwaldt M., Wickham R., Purl S.\& Tariman J., et. al. SelfCare Strategies to Cope With Taste Changes After Chemotherapy Oncol Nurs Forum.; 36(2): 47-56. 2009.

[16] Trüeb RN. Chemotherapy-Induced Alopecia. Elsevier Inc Med Surg (28):11-14.2009.

[17] Villasante AC, Herskovitz I, Mauro LM, Jimenez JJ. Chemotherapy-Induced Alopecia. J Clin Investigat Dermatol.;2(2): 8. 2014.

[18] Hamilton Health Sciences. Information for patients and families. Learning about chemotherapy treatment for patients and families. juravinski cancer center.p.14-16. 2012.

[19] Jayde V, Boughton M, Blomfield P. The experience of chemotherapy-induced alopecia for Australian women with ovarian cancer. Eur J Cancer Care 22(4): 503-0512. 2013.

[20] Mirfazaelian H, Namazi MR, aneshbod Y: Mees' lines. Scientific World Journal.;11:267-8. 2011.

[21] Kumar S., Diwan S. Dekate M .\& Goyal S. Mee's line following chemotherapy. Our Dermatol Online. 4(3): 382.2013. Available at sunilkumarmed@gmail.com.

[22] O'CallaghanV., Wuellner L. Understanding Chemotherapy A guide for people with cancer, their families and friends. 2nd edition. Cancer council Victoria. Available at www.cancervic.org.au. Page 34-35. 2012.

[23] Webber D, Guo Z, Mann S. Self-care in health: we can define it, but should we also measure it? SelfCare;4(5):101-106. 2013.

[24] Moursy A., M., E., S., and Ead A.,Y., S. Self-Care Practices of Chemotherapy Patients. Life Science Journal 2014;11(4).
Available at http://www.lifesciencesite.com. Pages 212-222

[25] Van der Meulen N, Jansen J, van Dulmen S et al. Interventions to improve recallof medical information in cancer patients: A systematic review of the literature. Psychooncology , 17: 857868. 2008.

[26] Lou Y. Self-management related fatigue- nausea- vomiting and oral mucositis in Chinese cancer patient. A dissertation for doctorate degree in philosophy. Faculty of health. Queensland university of technology.2011

[27] Campos M. P. O, Hassan B. J., Riechelmann R.et.al. Cancerrelated fatigue: a practical review. Annals of Oncology 22: 1273-1279, 2011.

[28] Lotfi-Jam K, Carey M, Jefford M et al. Non-pharmacologic strategies for managing common chemotherapy adverse effects: a systematic review. J Clin Oncol; 26(34): 5618-5629. 2008.

[29] Williams, P.D.,Lopez, V., Ying C.S., piamjariyakul,U., et., al. Symptom monitoring and self- care practices among oncology adults in china. Cancer Nursing, 33(3), 184-193. 2010.

[30] Gralla RG., Houlihan NG.\& Messner C. Understanding and Managing Chemotherapy Side Effects. Elsevier Oncology available at www.cancercare.org. p 6-10. 2010.

[31] Worthington $\mathrm{HV}$, et al. Interventions for preventing oral mucositis for patients with cancer receiving treatment (review) Cochrane Database of Systematic Reviews. http://www2.cochrane.org/reviews. 2011

[32] Portenoy R. K, Thaler H.T., Kornblith A.B., et. al. The Memorial Symptom Assessment Scale: An Instrument for the Evaluation of Symptom Prevalence, Characteristics and Distress. Eurq anJmml of CancnVol. 30A, No. 9,pp. 1326-36. 1994.

[33] Paice JA. Assessment of symptom clusters in people with cancer. Journal of the National Cancer Institute Monographs, (32). 98-102. 2004.

[34] Yildirim Y, Tokem Y, Bozkurt N, Fadiloglu C, Uyar M, Uslu R. Reliability and validity of the Turkish version of the Memorial Symptom Assessment Scale in cancer patients. Asian Pacific Journal of Cancer Prevention, 12 (12). 3389-96.2011.

[35] Kidd L. An exploration of patients' perceived control, self efficacy and involvement in self-care during chemotherapy for colorectal cancer. A dissertation for obtaining Degree of Doctor of Philosophy. Department of Nursing \& Midwifery University of Stirling. 2007.

[36] Department of Health. Self-care - a real choice: self-care support - a practical option. London: Department of Health. 2005.

[37] Buszewicz M et al,. 'Self-management of arthritis in primary care: randomized control trial', British Medical Journal; $333: 879.2006$.

[38] Laugsand, E.A., Jakobsen, G., Kaasa, S., Klepstad, P. Inadequate symptom control in advanced cancer patients across Europe. Support Care Cancer 19, 2005- 2014. 2011

[39] Kinnane N., Thompson L. Evaluation of the addition of videobased education for patients receiving standard prechemotherapy education. Eur J Cancer Care. 17: 328-339. 2008. 
[40] Bahrami, M. Meanings and aspects of Quality of Life (Q o L) for cancer patients:a descriptive exploratory qualitative study. Contemporary Nurse 39, 75-84. 2011

[41] King, C.R. Advances in how clinical nurses can evaluate and improve quality of life for individuals with cancer. Oncology Nursing Forum 33, 5-12.

[42] Thompson, E., Sola, I., Subirana, M. Non-invasive interventions for improving wellbeing and quality of life in patients with lung cancer e a systematic review of the evidence. Lung Cancer 50, 163-167. 2005

[43] Aslan, Ö., Vural, H., Kömürcü, S, ., Özet, A. The effects of nursing education role on cancer patients undergoing chemotherapy), Vol. 10. C.Ü. Hems, irelik Yüksekokulu Dergisi, pp. 15-28. 2006

[44] Aranda S., JeffordM. P., Yates K. et.al. Impact of a novel nurse-led prechemotherapy education intervention (ChemoEd) on patient distress, symptom burden, and treatment-related information and support needs: results from a randomised, controlled trial Annals of Oncology 23: 222-231.2012.

[45] Kav, S., Akdemir, N., The effect of self-care theory on controlling the side effects of cancer treatments MASCC/ISOO 16th International Symposium, Miami, FL, USA. Supportive Care in Cancer 12, 394. 2004

[46] Prutipinyo C., Maikeow K. and Sirichatiratana N. Self-care behaviours of chemotherapy patients.J Med Assoc Oncology Nursing Forum, 36/2, p. 47-56. 2012.

[47] Kangas M, Bovbjerg DH, Montgomery GH. Cancer-related fatigue: a systematic and meta-analysis review of nonpharmacological therapies for cancer patients. Psychological Bulletin. 134(5):700-741.2008.

[48] Morrow G., R. Cancer-related fatigue: causes, consequences and management. The Oncologist.;12 (suppl 1):1-3. 2007

[49] Cancer council. Understanding Chemotherapy. A guide for people with cancer, their families and friends. 2ed. Available at www.cancervic.org.auTreatment. 30-31. 2012.

[50] Thompson J, Silliman K \& Clifford D. E. Impact of an early education multimedia intervention in managing nutritionrelated chemotherapy side effects: a pilot study. Springer Plus
$2: 179$

Available

http://www.springerplus.com/content/2/1/179. 2013.

[51] American Cancer Society. Cancer facts and figures. Available at http://www.cancer.org/downloads/STT/CAFF.2007

[52] Miller M, Taylor A, Kearney N, Paterson G, WellsM, Roe L, et al. Evaluation of the feasibility and acceptability of an oral care diary by patients during chemotherapy. Int J Nurs Stud, 44:693-701. 2007.

[53] Frith H., Harcourt D., Fussell A. Anticipating an altered appearance: women undergoing chemotherapy treatment for breast cancer. Eur J Oncol Nurs, 11, 385-91. 2007.

[54] Macmillan Cancer Resource Centre. Coping withHair Loss Information for patients. East Cheshire NHS Trust.1-4. Available at www.macmillan.org.uk. 2012.

[55] KimIR., Cho J, Choi EK., Kwon IG et.al. Perception, Attitudes, Preparedness and Experience of ChemotherapyInduced Alopecia among Breast Cancer Patients: a Qualitative Study Asian Pacific J Cancer Prev, 13, 1383-1388. 2012.

[56] Rosman S. Cancer and stigma: experience of patients with chemotherapy-induced alopecia. Patient Educ Couns, 52, 3339. 2004.

[57] McGarvey EL, Baum LD, Pinkerton RC. Psychological sequelae and alopecia among women with cancer. Cancer Pract, 9, 283-289. 2001.

[58] National Cancer Institute. Chemotherapy and you. Availableat://www.cancer.gov/cancertopics/ chemotherapyand-you.pdf. 2011. Last accessed at February 5, 2014.

[59] American Cancer Society. Cancer Facts and Figures, Atlanta, Ga. 2013.

[60] Al-Omran H., Abu-Humaid M., Convener, Khader L., El-Hour M. Chemotherapy Guidelines\&Recommendations for Best Nursing Practice. Jordanian Nursing Council. 43-46. 2009.

[61] Polovich, M., White, J., \& Kelleher, L. Chemotherapy and Biotherapy Guidelines and Recommendations for Practice. Pittsburgh, PA:Oncology Nursing Society. 2007. 